\title{
The neural tube patterns vessels developmentally using the VEGF signaling pathway
}

\author{
Kelly A. Hogan ${ }^{1, *}$, Carrie A. Ambler ${ }^{1, \star}$, Deborah L. Chapman ${ }^{2}$ and Victoria L. Bautch ${ }^{1,3, \dagger}$ \\ ${ }^{1}$ Department of Biology, University of North Carolina at Chapel Hill, Chapel Hill, NC 27599-3280, USA \\ 2Department of Biological Sciences, University of Pittsburgh, Pittsburgh, PA 15260, USA \\ ${ }^{3}$ Carolina Cardiovascular Biology Center, University of North Carolina at Chapel Hill, Chapel Hill, NC 27599, USA \\ *These authors contributed equally to this work \\ †Author for correspondence (e-mail: bautch@med.unc.edu) \\ Accepted 8 December 2003
}

Development 131, 1503-1513

Published by The Company of Biologists 2004

doi:10.1242/dev.01039

\section{Summary}

Embryonic blood vessels form in a reproducible pattern that interfaces with other embryonic structures and tissues, but the sources and identities of signals that pattern vessels are not well characterized. We hypothesized that the neural tube provides vascular patterning signal(s) that direct formation of the perineural vascular plexus (PNVP) that encompasses the neural tube at mid-gestation. Both surgically placed ectopic neural tubes and ectopic neural tubes engineered genetically were able to recruit a vascular plexus, showing that the neural tube is the source of a vascular patterning signal. In mouse-quail chimeras with the graft separated from the neural tube by a buffer of host cells, graft-derived vascular cells contributed to the PNVP, indicating that the neural tube signal(s) can act at a distance. Murine neural tube vascular endothelial growth factor A (VEGFA) expression was temporally and spatially correlated with PNVP formation, suggesting it is a component of the neural tube signal. A collagen explant model was developed in which presomitic mesoderm explants formed a vascular plexus in the presence of added VEGFA. Co-cultures between presomitic mesoderm and neural tube also supported vascular plexus formation, indicating that the neural tube could replace the requirement for VEGFA. Moreover, a combination of pharmacological and genetic perturbations showed that VEGFA signaling through FLK1 is a required component of the neural tube vascular patterning signal. Thus, the neural tube is the first structure identified as a midline signaling center for embryonic vascular pattern formation in higher vertebrates, and VEGFA is a necessary component of the neural tube vascular patterning signal. These data suggest a model whereby embryonic structures with little or no capacity for angioblast generation act as a nexus for vessel patterning.

Key words: Vascular pattern, Neural tube, Midline, VEGFA, Mouseavian chimeras

\section{Introduction}

Multiple cellular processes contribute to forming the embryonic vasculature. These include the specification of mesodermal precursor cells called angioblasts, their differentiation into endothelial cells, and the migration and assembly of angioblasts and endothelial cells into vessels (Risau, 1997; Cleaver and Melton, 2003). These processes must be coordinated within the vascular lineage, and they must also interface with the developmental programs of other embryonic lineages. This coordination is called vascular patterning, and it results in a primary vessel network that is reproducible in both time and space. Angioblasts respond to signals produced by other tissues to pattern the embryonic vasculature (Noden, 1988; Poole and Coffin, 1989; Coffin and Poole, 1991). However, little is known about the identity of vascular patterning signals, and even less is known about how they act to pattern vessels.

Several well-characterized molecular pathways are implicated in vascular patterning, including the VEGF, Notch, ephrin and EDG pathways, as well as unidentified genes such as out-of-bounds (reviewed in Hogan and Kolodziej, 2002)
(Fong et al., 1995; Shalaby et al., 1995; Carmeliet et al., 1996; Pereria et al., 1999; Zhong et al., 2000; Graef et al., 2001; Lawson et al., 2001; Zhong et al., 2001; Childs et al., 2002). Moreover, there are at least two classes of vascular patterning signals. Short-range signals are produced locally and act via cell interactions at short distances, whereas long-range signals affect target cells at a distance from the source of the signal. The VEGF signaling pathway produces both short- and longrange information to pattern blood vessels. VEGFA-coated beads induce ectopic vessels both at the site of bead deposition and on the contralateral side of avian embryos, indicating that both local and long-range signals are set up by an exogenous source of VEGFA (Bates et al., 2003; Finkelstein and Poole, 2003). Endogenous sources of VEGF also provide vascular patterning signals at multiple levels. VEGF expression by retinal cells and neurons is associated with local vessel patterning in the retina and limb, respectively (Stone et al., 1995; Zhang et al., 1999; Mukouyama et al., 2002; Otani et al., 2002). The Vegfa locus produces several isoforms with different biochemical properties, and analysis of embryos lacking heparin-binding VEGFA isoforms suggests that matrix 
deposition of VEGFA is important to local patterning and branching (Park et al., 1993; Keyt et al., 1996; Carmeliet et al., 1999; Ng et al., 2001; Ruhrberg et al., 2002; Stalmans et al., 2002; Zelzer et al., 2002). Additionally, endogenous VEGF is associated with long-range vascular patterning in Xenopus, where VEGF secreted from a midline structure called the hypochord is thought to induce angioblasts to migrate from lateral areas to form the dorsal aorta (Cleaver and Krieg, 1998). However, the hypochord does not exist in avians and mammals, and no embryonic structures have been identified as sources of midline vascular patterning signals in higher vertebrates.

Nevertheless, important vascular beds are formed and patterned around the midline of higher vertebrates. The perineural vascular plexus (PNVP) is a capillary bed that forms around the developing brain and spinal cord. This plexus provides essential nutrients and oxygen to the developing neural tissue, and it is the source of vascular sprouts that subsequently invade and metabolically support the neural tissue. These PNVP-derived vessels go on to form the bloodbrain barrier that is critical to proper CNS function in the adult (Bar, 1980; Risau, 1986; Risau and Wolburg, 1990; Bauer et al., 1993). Although the invasion of angiogenic sprouts into neural tissue has been described, the developmental processes that pattern the PNVP have not been investigated. Both quailchick and mouse-quail chimera analysis identified somitederived precursor cells as an important source of endothelial cells that comprise the PNVP (Wilting et al., 1995; Klessinger and Christ, 1996; Pardanaud et al., 1996; Pardanaud and Dieterlen-Lievre, 1999; Ambler et al., 2001). Moreover, our recent analysis of ES cell-derived grafts showed that VEGF signaling is involved in vascular patterning around the midline of higher vertebrates (Ambler et al., 2003). However, important questions remain unanswered, including the source of the signal(s) that act on somite-derived angioblasts to pattern the PNVP and the importance of VEGF in this process.

We have asked whether midline structures, specifically the neural tube, provide signals to pattern the PNVP of higher vertebrates. We show that the neural tube is the source of a vascular patterning signal that acts on the PNVP, and that VEGFA is a crucial component of this signal. These results provide the first identification of a midline signaling center that patterns vessels in higher vertebrates, and they suggest a model whereby embryonic structures with little or no capacity for angioblast generation act as a nexus for vessel patterning, and thus provide for their own sustenance.

\section{Materials and methods}

\section{Mice}

B6129S-Gtrosa26 (ROSA26) mice (Friedrich and Soriano, 1991) (The Jackson Laboratory) were bred and genotyped as described (Ambler et al., 2001). Flt1 ${ }^{+/}$mice (Fong et al., 1995) (gift of G. Fong) were bred to $\mathrm{TgN}(\mathrm{GFPU}) 5 \mathrm{Nagy}(e G F P)^{+/+}$mice (Hadjantonakis et al., 1998) (The Jackson Laboratory) to obtain $\mathrm{Flt1}^{+/-}$, e $\mathrm{GFP}^{+/+}$males, which were bred to wild type CD1 females (Charles River) to obtain embryos. Embryos from the $\mathrm{Flt1}^{+/-}, e \mathrm{GFP}^{+/+}$crosses were genotyped by $\beta$-galactosidase $(\beta$-gal) detection after surgical manipulation. C57BL/6-J-Kdr ${ }^{\mathrm{tm} 1 / \mathrm{rt}}$ males hemizygous for the Flk1 gene (Shalaby et al., 1995) (The Jackson Laboratory) were maintained on a CD1 background and intercrossed to females hemizygous for the Flkl gene to obtain embryos. All embryos were genotyped by PCR as described (Shalaby et al., 1995). $T b x 6^{t m 1 P a}$ heterozygous mice were maintained on a mixed C57B16/J 129Sv/Ev background. Tbx6 homozygous mutant embryos and control littermates were derived from heterozygous inter se matings. These embryos were genotyped as previously described (Chapman and Papaioannou, 1998). Vegf-lacZ$K 1^{+/-}$mice (Vegf-lacZ) (Miquerol et al., 1999) were bred to wild-type CD1 females (Charles River) to obtain embryos.

\section{Embryo manipulations}

Noon of the day of the mouse vaginal plug was considered 0.5 days post coitum (dpc). Mouse embryos were dissected at $8.5 \mathrm{dpc}$ into M2 Medium (Quinn et al., 1982) containing pen/strep (penicillin (100 $\mathrm{U} / \mathrm{ml}) /$ streptomycin $(100 \mathrm{ng} / \mathrm{ml})$ ). Embryos were pinned onto a Sylgard (Dow Corning) dish in M2 medium with tryp/panc [5 $\mu \mathrm{g} / \mathrm{ml}$ trypsin (Sigma) $/ 25 \mu \mathrm{g} / \mathrm{ml}$ pancreatin (Sigma)]. To loosen the tissues, embryos were incubated in M2 medium with tryp/panc for 1 minute before presomitic mesoderm or axial structures were surgically dissected using a sharpened tungsten needle. Dissected tissues were placed in PBS with 10\% FBS containing pen/strep, then placed in collagen gels or quail hosts.

Fertilized Japanese quail eggs (CBT Farms, Chestertown, MD) were incubated at $37^{\circ} \mathrm{C}$ for 48 hours to the $\mathrm{HH} 10-13$ stage (Hamburger and Hamilton, 1951). Quails were used (1) to provide a source of axial structures (notochord or neural tube) for explant cocultures, or (2) as hosts for axial structures or mouse presomitic mesoderm. For explant co-cultures, quail embryos were removed into Tyrodes buffer, then pinned onto a Sylgard dish in Tyrodes buffer with tryp/panc. Caudal axial structures (at the level of presomitic mesoderm) were surgically dissected using a sharpened tungsten needle and the graft was transferred to PBS containing $10 \%$ heatinactivated FBS before placement in collagen. Quail host embryos were surgically prepared according to graft type. For neural tube grafts, the intermediate mesoderm was separated from the lateral plate mesoderm. For presomitic mesoderm grafts, the lateral region of the quail presomitic mesoderm was removed. After graft placement and addition of pen/strep, the eggs were sealed with Parafilm and incubated for 48 or 72 hours at $37^{\circ} \mathrm{C}$ in a humidified incubator.

\section{$\beta$-Galactosidase detection and immunohistochemistry}

Quail embryos containing either ROSA26 neural tube grafts or $\mathrm{Flkl^{+/- }}$ mouse presomitic mesoderm grafts were processed for whole-mount $\beta$-gal detection as previously described (Ambler et al., 2001). Briefly, embryos were sacrificed 48-72 hours post surgery, rinsed in PBS, and fixed in $4 \%$ paraformaldehyde (PFA) for 15-20 minutes at room temperature. Chimeras were washed twice for 10 minutes in wash buffer [(0.1 M phosphate buffer, $\mathrm{pH} 7.3), 0.1 \%$ sodium desoxycholate, $0.02 \%$ NP40, $0.05 \%$ BSA (Sigma)], then transferred to wash buffer containing $1 \mathrm{mg} / \mathrm{ml} \mathrm{X-gal} \mathrm{(Sigma),} 5 \mathrm{mM}$ ferrocyanide and $5 \mathrm{mM}$ ferricyanide. After incubation for $14-18$ hours at $37^{\circ} \mathrm{C}$ in the dark, embryos were post fixed in $4 \%$ PFA and stored at $4{ }^{\circ} \mathrm{C}$ until embedded. Vegf-lac $Z^{+/-}$or ${ }^{+/+}$embryos were processed for whole-mount $\beta$ galactosidase detection similarly with one exception - these embryos were pre- and post-fixed in $0.2 \%$ glutaraldehyde (in $0.1 \mathrm{M}$ phosphate buffer containing $5 \mathrm{mM}$ EGTA and $2 \mathrm{mM} \mathrm{MgCl}_{2}$ ).

Whole-mount platelet endothelial cell-adhesion molecule (PECAM) immunohistochemistry [adapted from Dent et al. (Dent et al., 1989)], was performed as described (Ambler et al., 2001; Ambler et al., 2003). Embryos were stored in PBS until photographed with an Olympus SZH10 dissecting microscope. Embryos were embedded, sectioned and mounted as previously described (Ambler et al., 2001). QH1 staining was performed on sections as previously described (Ambler et al., 2001) and viewed with a Nikon Opitphot 2 microscope.

\section{Collagen gel explants}

Mouse presomitic mesoderm was either cultured alone or in combination with quail axial structures. The collagen [final concentration $1.5 \mathrm{mg} / \mathrm{ml}$ (Sigma)] contained one part $10 \times(1 \mathrm{M})$ HEPES, one part $10 \times$ minimal essential media (MEM), one part 


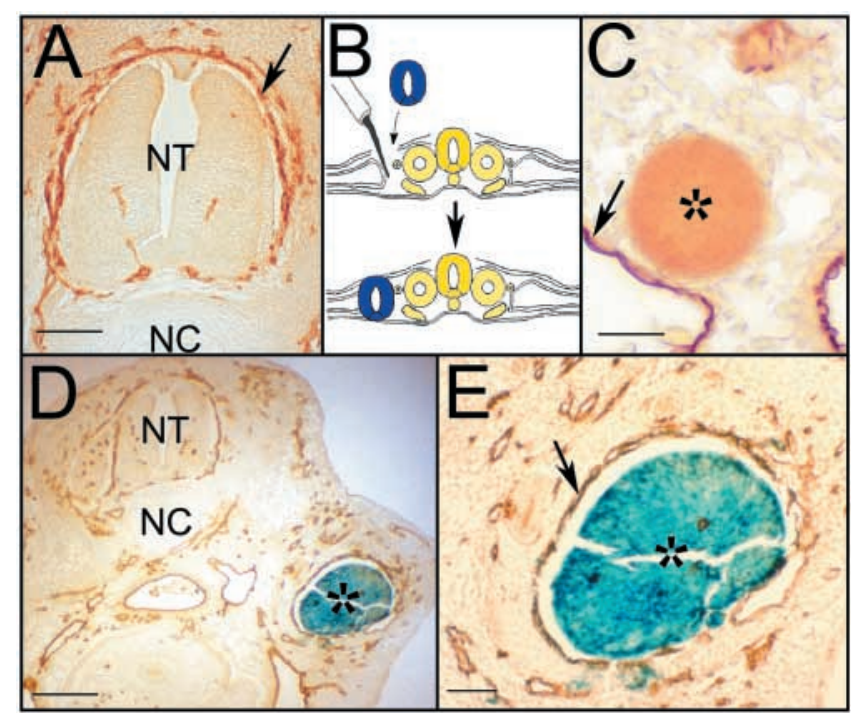

Fig. 1. The neural tube directs PNVP formation in vivo.

(A) Transverse section through the trunk of a $\mathrm{HH}$ stage 24 quail embryo labeled with the QH1 antibody (brown). The arrow indicates a ring of vessels around the neural tube termed the perineural vascular plexus (PNVP). (B) In ovo manipulations placing a mouse neural tube (blue) between the lateral plate and intermediate mesoderm in a quail host. (C) Section of a HH 24 stage quail embryo with an implanted acrylic bead (asterisk) stained with QH1 antibody (purple). Note that a large vessel is positioned near the bead (arrow), but no vascular plexus surrounds the bead. (D) Low magnification of a transverse section through a $\mathrm{HH}$ stage 24 quail host with a grafted $\mathrm{ROSA}^{+/-}$mouse neural tube (asterisk), 3 days post-surgery. Chimeric embryos were whole-mount stained for $\beta$-gal (blue), then sectioned and reacted with QH1 antibody (brown). (E) Higher magnification of $D$. The arrow indicates a host-derived vascular plexus surrounding the grafted neural tube. $n \geq 5$ for all in ovo manipulations.

NC, notochord; NT, neural tube. Scale bar: $100 \mu \mathrm{m}$ in A; $50 \mu \mathrm{m}$ in $\mathrm{C}, \mathrm{E} ; 200 \mu \mathrm{m}$ in D.

sodium bicarbonate $(11.76 \mathrm{mg} / \mathrm{ml})$ and seven parts rat tail collagen type I $(2.14 \mathrm{mg} / \mathrm{ml}$, resuspended in $3 \%$ sterile acetic acid). This solution was stored on ice until incubated at $37^{\circ} \mathrm{C}$ for gelling. A base layer of collagen was gelled into wells of a 96-well tissue culture plate and stored at $37^{\circ} \mathrm{C}$. Explants were added to liquid collagen $(35 \mu \mathrm{l})$ and placed over the gelled collagen in wells at $37^{\circ} \mathrm{C}$ for 10 minutes. After gelling, basal medium [DMEM-H, 10\% heat inactivated FBS (Hyclone), pen/strep and gentamicin $(50 \mathrm{ng} / \mathrm{ml})]$, or basal medium with $30 \mathrm{ng} / \mathrm{ml}$ recombinant human VEGF164 (R\&D Systems), 25 $\mathrm{ng} / \mathrm{ml}$ human recombinant bFGF (Sigma), $1 \mu \mathrm{g} / \mathrm{ml} \mathrm{Flt/Fc} \mathrm{(R \& D}$ Systems) or $10 \mu \mathrm{M}$ SU5416 (SUGEN) was added. Explant cultures were then incubated for $24-72$ hours at $37^{\circ} \mathrm{C}$ in a humidified $5 \% \mathrm{CO}_{2}$ incubator. Cultures containing $e G F P^{+/-}$tissues were viewed with epiflourescence and photographed before fixation. Cultures were fixed in $0.2 \%$ glutaraldehyde (in $0.1 \mathrm{M}$ phosphate buffer containing $5 \mathrm{mM}$ EGTA and $2 \mathrm{mM} \mathrm{MgCl}_{2}$ ) for 20 minutes before $\beta$-gal staining (described above). Stained explants were then photographed on an Olympus IX50 inverted microscope.

\section{Results}

\section{The neural tube directs assembly of the perineural vascular plexus in vivo}

A vascular plexus reproducibly forms around the vertebrate neural tube at midgestation (Nakao et al., 1988). This

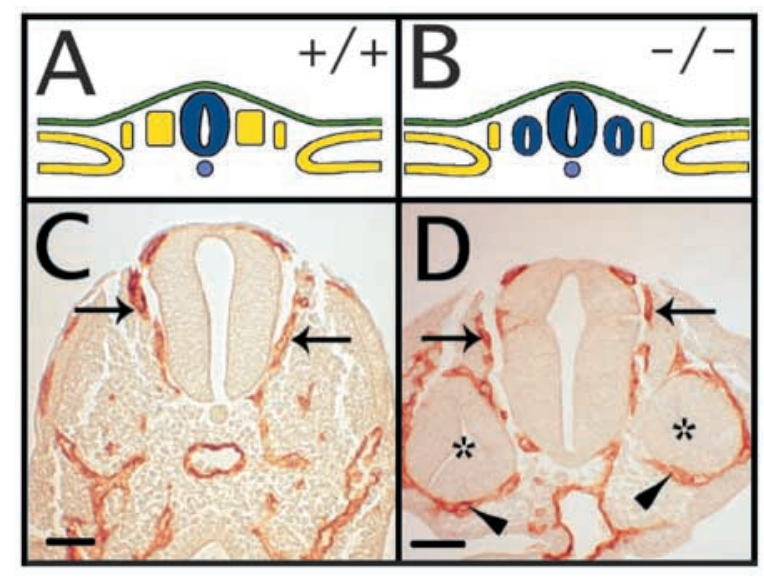

Fig. 2. The multiple neural tubes of Tbx6 mutant embryos each recruit a PNVP. (A,B) Diagram of a transverse section through the caudal region of a wild-type (A) and Tbx6 homozygous mutant (B) embryo depicting the differences in Tbx6 mutant embryos. Note that somitic tissue (yellow) does not form in the Tbx6 mutants, but ectopic neural tubes (blue) form on both sides of the main neural tube (blue). (C,D) Transverse sections through the posterior trunk of 10.5 dpc PECAM-stained wild-type (C) and Tbx6 mutant (D) embryos. The PNVP around the central neural tube is present in both embryos (arrows in C,D), and the ectopic neural tubes (denoted with asterisks in the Tbx6 mutant embryo) are also surrounded by a vascular plexus (arrowheads in D). Scale bar: $70 \mu \mathrm{m}$ in C,D.

perineural vascular plexus (PNVP) is visualized in the quail with QH1 (Fig. 1A), an antibody specific for quail endothelial cells and a subset of hematopoietic cells (Pardanaud et al., 1989). To determine if the neural tube provides a patterning signal responsible for recruitment and assembly of perineural vessels, we transplanted mouse neural tubes lateral to the endogenous neural tube in quail embryos (Fig. 1B), and analyzed the effect on the host vasculature. Mouse neural tubes were derived from ROSA26 heterozygous embryos to allow for identification of mouse tissue via the ubiquitously expressed lacZ transgene. Whole-mount visualization after $\beta$ galactosidase ( $\beta$-gal) staining showed that the neural tube grafts were well incorporated (data not shown). Analysis of sections stained with QH1 showed quail blood vessels immediately adjacent to the grafted mouse neural tube, and they assembled in a structure resembling the PNVP (Fig. 1DE, compare Fig. 1A with 1E). To determine whether vascular plexus formation was specific to the neural tube, both acrylic beads and avian notochords were grafted using similar embryological manipulations. Neither the beads (Fig. 1C) nor the notochord (data not shown) elicited a vascular plexus, indicating that the vascular plexus surrounding the neural tube was not the result of encapsulation of a foreign body. Thus, these results demonstrate that the neural tube is a source of a signal that directs formation of a vascular plexus.

We next asked whether ectopic neural tubes that develop in vivo, owing to a mis-specification of paraxial mesoderm, could recruit a PNVP (Fig. 2). The mouse Tbx6 mutation results in the formation of ectopic neural tubes that replace the paraxial somites that normally form on each side of the neural tube in the trunk (Fig. 2A,B) (Chapman and Papaioannou, 1998). $T b x 6^{t m 1 P a}$ homozygous mutant embryos $(10.5 \mathrm{dpc})$ stained for the endothelial marker PECAM show a disorganized vascular 
pattern in whole mount (data not shown). Although the pattern of head vessels appears normal, the regular intersomitic vessels are absent in the posterior half of the mutant embryos, consistent with the absence of posterior somites. In sections, the ectopic neural tubes are each surrounded by a vascular plexus (Fig. 2C,D). Interestingly, the PNVP around the central neural tube is intact, suggesting that the PNVP that forms around the ectopic neural tubes does not compete with the normal PNVP for angioblasts. These findings support the hypothesis that the neural tube is a source of positive patterning signal(s) for developing vessels in the embryo.

To determine whether the neural tube-derived vascular patterning signal could act at a distance, we asked whether a buffer placed between the target cells and the signal source prevented the target cells from responding to the signal (Fig. 3 and Table 1). In our previous analyses using mouse-avian chimeras, mouse presomitic mesoderm grafts were initially placed immediately adjacent to the neural tube (Ambler et al., 2001). Thus, we modified our protocol to leave the medial region of the host presomitic mesoderm intact, setting up a buffer of several cell layers of quail mesoderm between the graft and the host neural tube (Fig. 3A). Presomitic mesoderm grafts were derived from either wild-type $(+/+)$ or $\mathrm{FlkI}^{+/-}$ $\left(\mathrm{Kdr}^{+/-}\right.$- Mouse Genome Informatics) mouse embryos. The latter embryos have lacZ inserted at the Flkl locus to allow for identification of graft-derived vascular cells via $\beta$-gal staining. Wild-type (+/+) graft vascular cells were identified by PECAM expression. Graft-derived vascular cells were found in host vascular beds around the midline and limb after 48 or 72 hours (Fig. 3B-E). Overall, 36\% of the chimeras scored positive for graft-derived cells in the PNVP (Fig. 3F,G; Table 1). However, $43 \%$ of the 72 hour grafts were PNVP positive, while only $25 \%$ of the 48 hour grafts had graft cells in the PNVP. This trend suggests that incorporation of angioblasts from lateral areas into the PNVP is a time-dependent process. These findings show that the neural tube-derived vascular patterning signal can affect angioblast migration despite the presence of a buffer, indicating that the signal can act over a distance and does not require direct cell contact.

We next turned our attention towards the molecular composition of the neural tube vascular patterning signal(s). We hypothesized that the VEGFA signaling pathway might be a component of the signal, because it locally directs vascular patterning, and it is also critical to stem cell-derived angioblast patterning around the midline in higher vertebrates (Stone et al., 1995; Zhang et al., 1999; Mukouyama et al., 2002; Otani et al., 2002; Ambler et al., 2003). The mouse PNVP forms around the neural tube from anterior to posterior between 8.5 and $10.5 \mathrm{dpc}$ of mouse development (Evans, 1909; Nakao et al., 1988) (M. Kalil, C.A.A. and V.L.B., unpublished). To determine if VEGFA is expressed when the PNVP is assembled and thus a candidate for involvement in this process, we examined both VEGF expression and PNVP formation in mouse embryos at E8.5-9.5. We analyzed embryos with $l a c Z$ knocked into one copy of the Vegfa gene such that they are phenotypically normal (Miquerol et al., 1999), and littermates matched for somite number were stained with PECAM (Fig. 4). Neural tube cells expressing $\beta$-gal from the Vegfa locus were seen in anterior regions of E8.5 embryos, and at this level the PNVP was partially formed (Fig. 4E,F). However, more posterior levels in the same embryos had no detectable neural

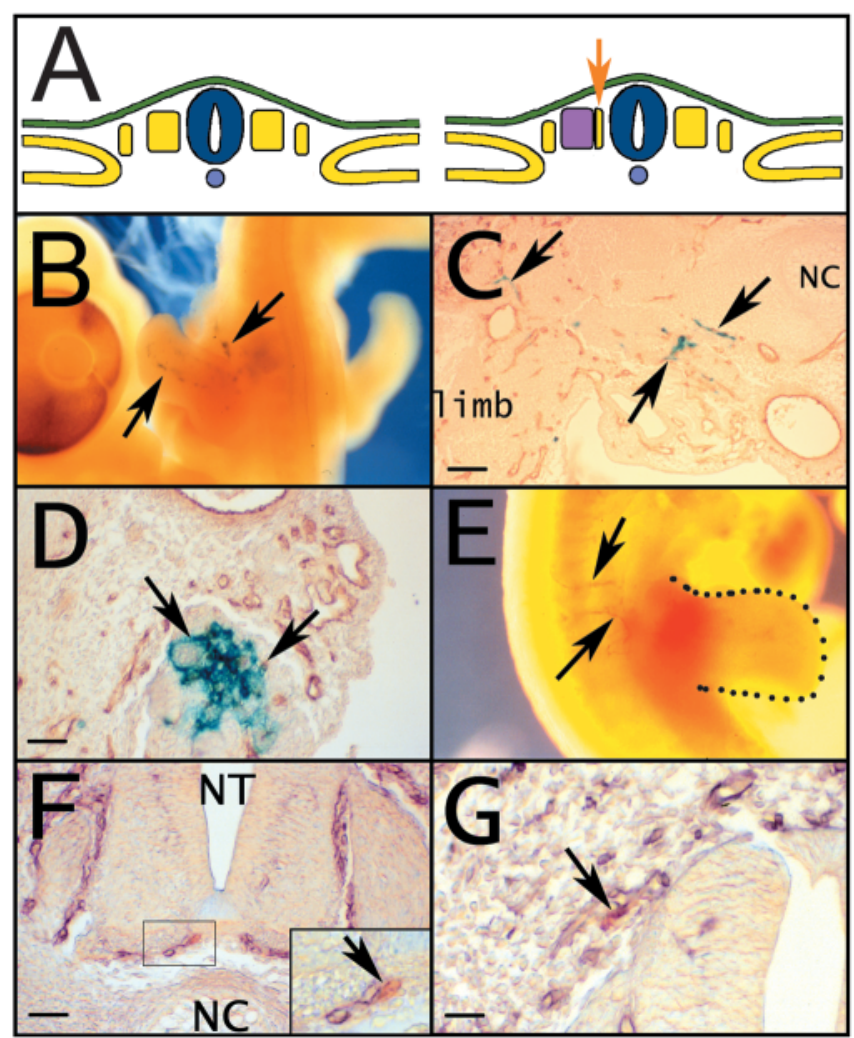

Fig. 3. The neural tube-derived vascular patterning signal induces target cells at a distance. Mouse presomitic mesoderm grafts were placed in quail embryos adjacent to host medial presomitic mesoderm, in a cavity made by removal of quail lateral presomitic mesoderm. Grafts were either $F l k 1^{+/-}$(lacZ in Flk1 locus) (B-D) or wild type (E-G), and after incubation for 48 or 72 hours, chimeric embryos were fixed and stained for $\beta$-gal (B-D) or PECAM (E-G). (A) In ovo manipulations. The orange arrow indicates the medial quail presomitic mesoderm that is situated between the mouse graft (purple rectangle) and the host neural tube (dark blue). (B) Chimera incubated for 72 hours and stained for $\beta$-gal. Arrows indicate mouse graft-derived vascular cells (blue) in the trunk and limb vessels of the quail host. (C,D) Sections through the trunk of the chimeric embryo in B. $\beta$-Gal-positive vessels are highlighted by arrows in the intersomitic and limb vascular beds (C) and the kidney rudiment (D). (E) Chimera incubated for 72 hours and stained for PECAM. Arrows indicate graft-derived vascular cells (brown) in host intersomitic and limb vessels. (F,G) Sections through the neural tube of the chimera in E stained with PECAM antibody (brown) to visualize mouse graftderived vascular cells, and QH1 antibody (purple) to visualize host vessels. (F) PECAM-positive cells (brown) identified in the ventral region of the PNVP. The inset shows a higher magnification of this vessel (arrow indicates PECAM-positive graft-derived cells). (G) A different region of the neural tube shows PECAM-positive endothelial cells (arrow) in a quail PNVP vessel. Scale bar: $80 \mu \mathrm{m}$ in $\mathrm{C} ; 40 \mu \mathrm{m}$ in $\mathrm{D}, \mathrm{F} ; 20 \mu \mathrm{m}$ in $\mathrm{G}$.

tube $\beta$-gal expression and no PNVP (Fig. 4C,D). The posterior E9.5 embryos resembled the anterior E8.5 embryos in having scattered $\beta$-gal-positive neural tube cells and a partially formed PNVP (Fig. 4G,H). However, the anterior level of E9.5 embryos showed somewhat stronger $\beta$-gal expression, and at this level the PNVP surrounded most of the neural tube (Fig. $4 \mathrm{I}, \mathrm{J})$. Interestingly, the $\beta$-gal-expressing cells were more localized to the lateral edge of the neural tube at this and later 
stages (Fig. 4I; data not shown). This finding suggests that in the mouse neural tube, VEGFA expression that is initially diffuse becomes localized to the outer edge with time,

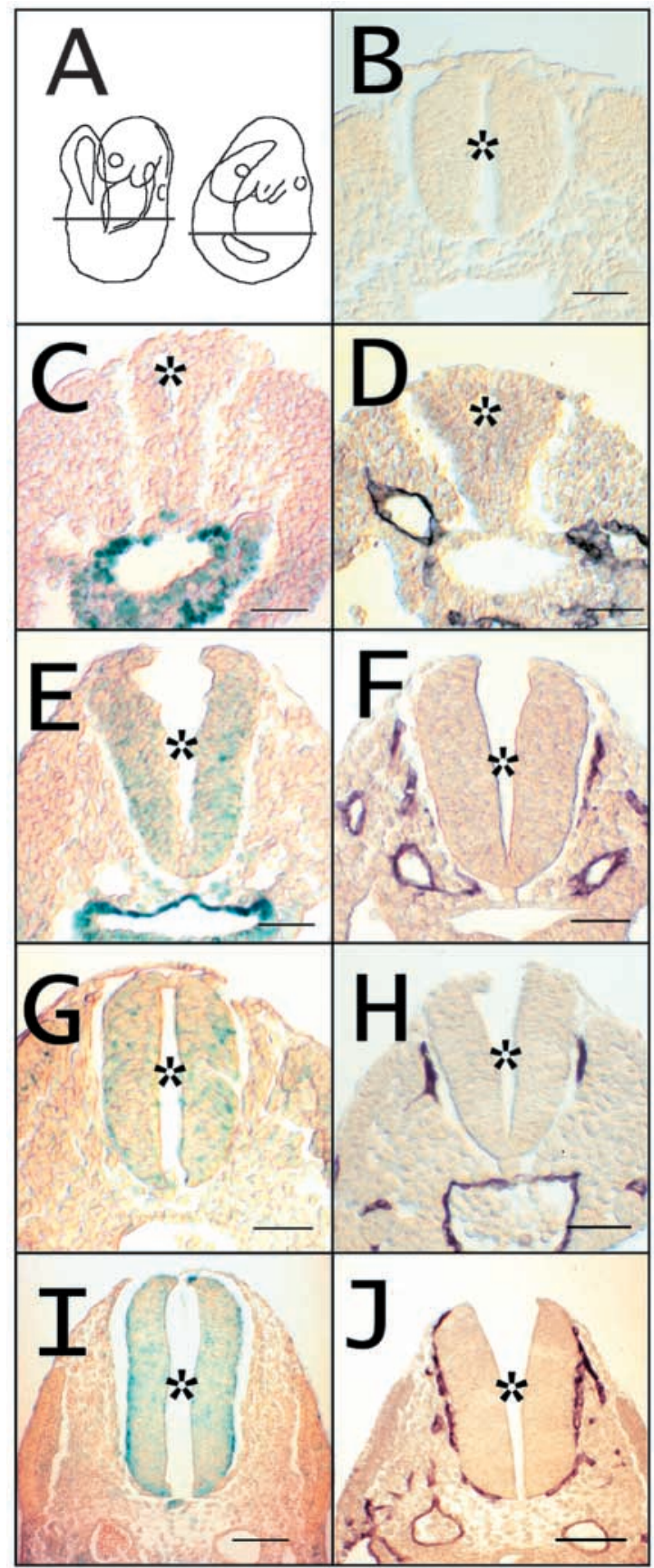

consistent with its potential role in vascular patterning. Weak Vegf mRNA expression is detected in the ventral neural tube at stage E2 in the quail, and it is increased at E3 when the PNVP is formed (Aitkenhead et al., 1998). Thus, VEGFA is expressed temporally and spatially as predicted for a neural tube vascular patterning signal, and it is a candidate to be involved in vascular patterning from the neural tube.

\section{VEGFA and the neural tube form a somite-derived vascular plexus ex vivo}

To further dissect the molecular composition of the neural tube vascular patterning signal, we developed a collagen gel explant model (Fig. 5). Presomitic mesoderm was removed from $8.5 \mathrm{dpc} \mathrm{Flt1}^{+/-}$, eGFP $\mathrm{FP}^{+/-}$mouse embryos and embedded in collagen for further analysis. Endothelial cells/progenitors were identified as $\beta$-gal-positive cells that expressed lac $Z$ from the FLT1 locus (Fong et al., 1995), while eGFP was expressed by all explant cells. The explants were negative for $\beta$-gal expression when initially set up (data not shown) (Ambler et al., 2001). After 72 hours in basal growth conditions, only a few $\beta$-gal-positive cells were seen (Fig. 5A, arrow), although vigorous expression of eGFP showed that the explants had grown considerably and were healthy (Fig. 5B). However, a robust primitive vascular network was seen when the explants were incubated with added VEGFA (Fig. 5C,D). By contrast, bFGF addition produced only a few small clumps of $\beta$-galpositive cells (Fig. 5E,F), and no plexus formed even in a range of bFGF concentrations (5-100 ng/ml, data not shown),

Fig. 4. VEGFA expression correlates with formation of the PNVP. E8.5-9.5 Vegf-lac $Z^{+-}$embryos were dissected and processed for either $\beta$-gal or PECAM antibody staining. (A) An embryo at E8.59.0 with $\sim 12$ somites (left), and an embryo at E9.5 with 20-25 somites (right). The lines indicate the level of transverse sections shown in B-J. (B) Posterior section through an E9.5 wild-type embryo $\beta$-gal stained as a negative control. (C,D) Posterior sections through E8.5 Vegf-lac $Z^{+/-}$embryos stained for $\beta$-gal (C) or PECAM (D). Note the lack of $\beta$-gal staining in the neural tube (asterisk) and the $\beta$-gal reactivity in the underlying endoderm in $\mathrm{C}$, and the lack of vessels around the neural tube in D. (E,F) Anterior sections through E8.5 Vegf-lac $Z^{+/}$embryos stained for $\beta$-gal (E) or PECAM (F). Note the diffuse $\beta$-gal reactivity in the neural tube, and the stronger signal from the underlying endoderm in $\mathrm{E}$, and the partial PNVP in $\mathrm{F}$. $(\mathrm{G}, \mathrm{H})$ Posterior sections through E9.5 Vegf-lac $\mathrm{Z}^{+/}$embryos stained for $\beta$-gal $(\mathrm{G})$ or PECAM $(\mathrm{H})$. (I,J) Anterior sections through E9.5 Vegf-lac $Z^{+/}$embryos stained for $\beta$-gal (I) or PECAM (J). Note the stronger $\beta$-gal reactivity that is partially localized to the lateral edge of the neural tube in I, and the fully formed PNVP in J. Asterisks indicate the central canal of the neural tube in B-J. Scale bars: $50 \mu \mathrm{m}$ in $\mathrm{B}-\mathrm{H} ; 100 \mu \mathrm{m}$ in $\mathrm{I}, \mathrm{J}$. A is reproduced, with permission, from Kaufman (Kaufman, 1992).

Table 1. Location of mouse presomitic mesoderm grafts placed laterally in quail hosts

\begin{tabular}{|c|c|c|c|c|c|c|}
\hline & \multicolumn{6}{|c|}{ Area containing graft endothelial cells } \\
\hline & PNVP & Kidney & Cardinal vein & $\begin{array}{l}\text { Intersomitic } \\
\text { vessels }\end{array}$ & Limb & Dorsal aorta \\
\hline 48-hour incubation & $1 / 4$ & $4 / 4$ & $3 / 4$ & $3 / 4$ & $2 / 3^{*}$ & $0 / 4$ \\
\hline 72-hour incubation & $3 / 7$ & $7 / 7$ & $1 / 7$ & $5 / 7$ & $3 / 7$ & $1 / 7$ \\
\hline Totals (\% of total) & $4 / 11(36 \%)$ & $11 / 11(100 \%)$ & $4 / 11(36 \%)$ & $8 / 11(73 \%)$ & $5 / 10(50 \%)$ & $1 / 11(9 \%)$ \\
\hline
\end{tabular}


indicating that the vascular network was specific to VEGFA. The VEGFA-induced vascular plexus was also positive for a second endothelial marker, FLK1 (see Fig. 8). Thus, formation

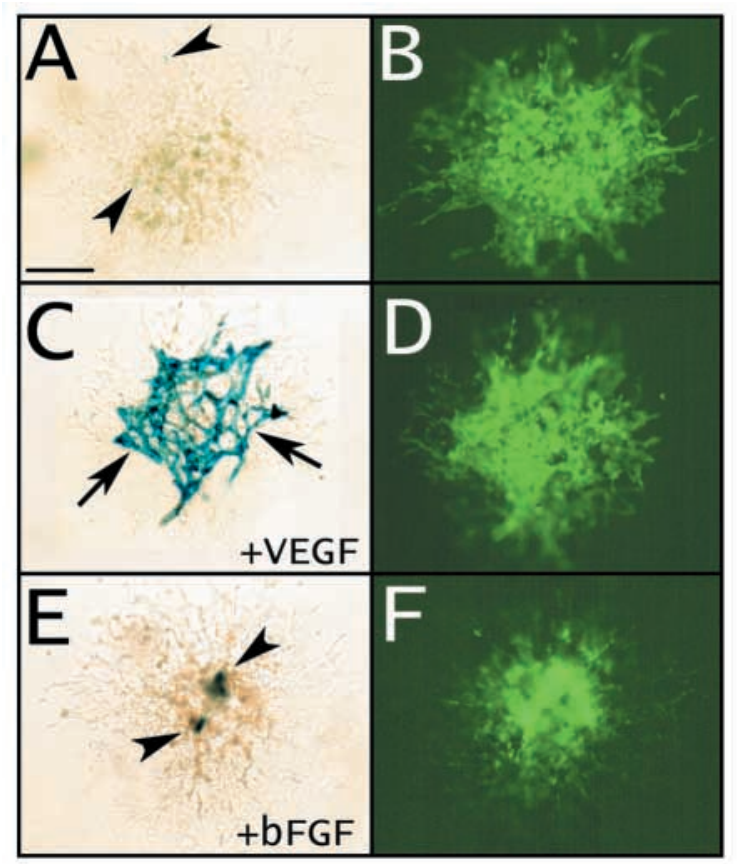

Fig. 5. Presomitic mesoderm explants form VEGF-dependent vascular networks. $8.5 \mathrm{dpc} F l t 1^{+/-}$, $e G F P^{+/-}$mouse presomitic mesoderm explants were embedded in collagen gels and cultured for 72 hours. Explants were stained for $\beta$-gal activity (A,C,E), and the same explants were visualized for eGFP expression (B,D,F). Explants were incubated with basal medium alone (A,B), or with added $30 \mathrm{ng} / \mathrm{ml}$ VEGFA (C,D) or $25 \mathrm{ng} / \mathrm{ml} \mathrm{bFGF}$ (E,F). $n \geq 7$ for all three conditions. The arrows in $\mathrm{C}$ indicate the vascular plexus, and the arrowheads in $\mathrm{A}$ and $\mathrm{E}$ indicate $\beta$-gal positive (blue) presumptive vascular cells. Scale bar: $200 \mu \mathrm{m}$ for all panels.

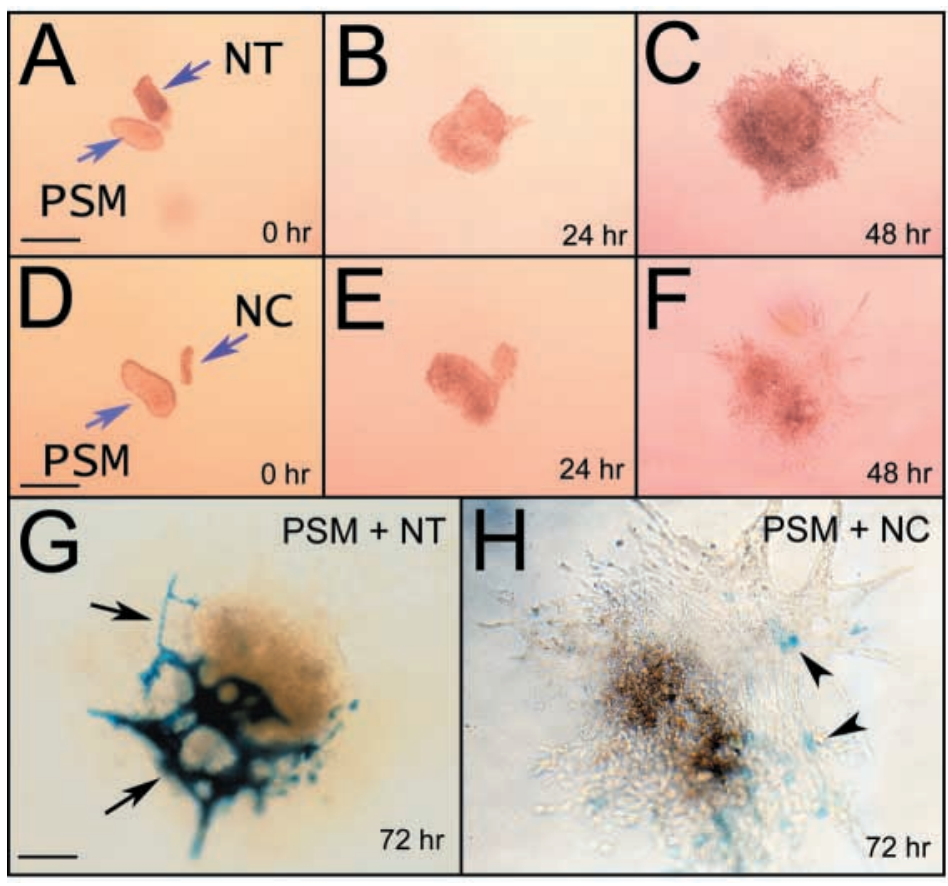

of a presomitic mesoderm-derived vascular plexus requires VEGFA in this explant model.

To determine if the neural tube could substitute for VEGFA and induce a vascular plexus in the explant model, we cocultured neural tube and presomitic mesoderm explants (Fig. 6). Co-culture of quail neural tube and $\mathrm{Fltl}^{+/-}$mouse presomitic mesoderm resulted in the formation of a presomitic mesoderm-derived vascular plexus (Fig. 6A-C,G). This plexus was similar in complexity to the presomitic mesoderm-derived vascular plexus formed in the presence of VEGFA (compare Fig. 5C with Fig. 6G). The vascular network formed was specific to the neural tube, because co-culture with quail notochord did not induce a similar response (Fig. 6 D-F,H). Thus, the neural tube can substitute for VEGFA in the induction of a vascular plexus from presomitic mesoderm.

\section{The VEGF signaling pathway is required for formation of the neural tube-induced vascular plexus}

We next asked whether the VEGF signaling pathway was a crucial component of the neural tube-derived vascular plexus signal. To address this question, we blocked VEGF signaling through the use of pharmacological inhibitors. We used two pharmacological agents that affect the VEGF pathway differently (Fig. 7). The first, Flt/Fc, is a small region of the FLT1 receptor that binds VEGF and prevents it from binding and activating VEGF receptors (Ferrara and Davis-Smyth, 1997). The addition of Flt/Fc to the $\mathrm{Flt1}^{+/-}, e \mathrm{GFP}^{+/-}$presomitic mesoderm/neural tube co-cultures resulted in the complete absence of a vascular plexus after 72 hours (Fig. 7C,D). A second pharmacological inhibitor, SU5416, directly inhibits FLK1, the main signaling receptor for VEGF (Fong et al., 1999). Addition of SU5416 to the co-cultures also resulted in a complete inhibition of vascular plexus formation, similar to the Flt/Fc experiments (Fig. 7E,F). Moreover, the complete lack of vascular cells in the presence of the inhibitors suggested to us that our basal conditions may include trace amounts of

VEGF (Fig. 5A). Thus, interference with VEGF signaling, either by competitive binding of VEGF or by receptor inhibition, blocked neural tube-dependent formation of a vascular plexus from presomitic mesoderm.

Finally, we blocked the VEGF signaling pathway genetically through use of $F l k 1^{-1-}$ presomitic mesoderm explants. $F l k 1^{-1-}$ mutant explants were incubated with VEGFA or co-cultured with neural tubes (Fig. 8). In contrast to hemizygous $\left(F l k 1^{+-}\right)$presomitic mesoderm explants that form a vascular plexus in the presence of

Fig. 6. Neural tube-dependent vascular plexus formation in presomitic mesoderm explants. Flt ${ }^{+/-}$mouse presomitic mesoderm grafts (PSM) $(8.5 \mathrm{dpc})$ were co-cultured with HH1013 stage quail neural tubes (NT) or notochords (NC) in collagen gels for 72 hours. Individual co-cultures were photographed at 0 $(\mathrm{A}, \mathrm{D}), 24(\mathrm{~B}, \mathrm{E})$ or 48 hours $(\mathrm{C}, \mathrm{F})$ to demonstrate the growth of the tissues. The same cultures were then fixed at 72 hours and stained for $\beta$-gal $(\mathrm{G}, \mathrm{H})$. The purple arrows indicate the respective tissues and the black arrows indicate the vascular plexus that forms in PSM/NT co-cultures. The arrowheads indicate the few $\beta$-gal positive presumptive vascular cells seen in PSM/NC cocultures. $n>10$ for PSM/NT co-cultures and $n=3$ for PSM/NC cocultures. Scale bars: $350 \mu \mathrm{m}$ in A-F; $140 \mu \mathrm{m}$ in G,H. 


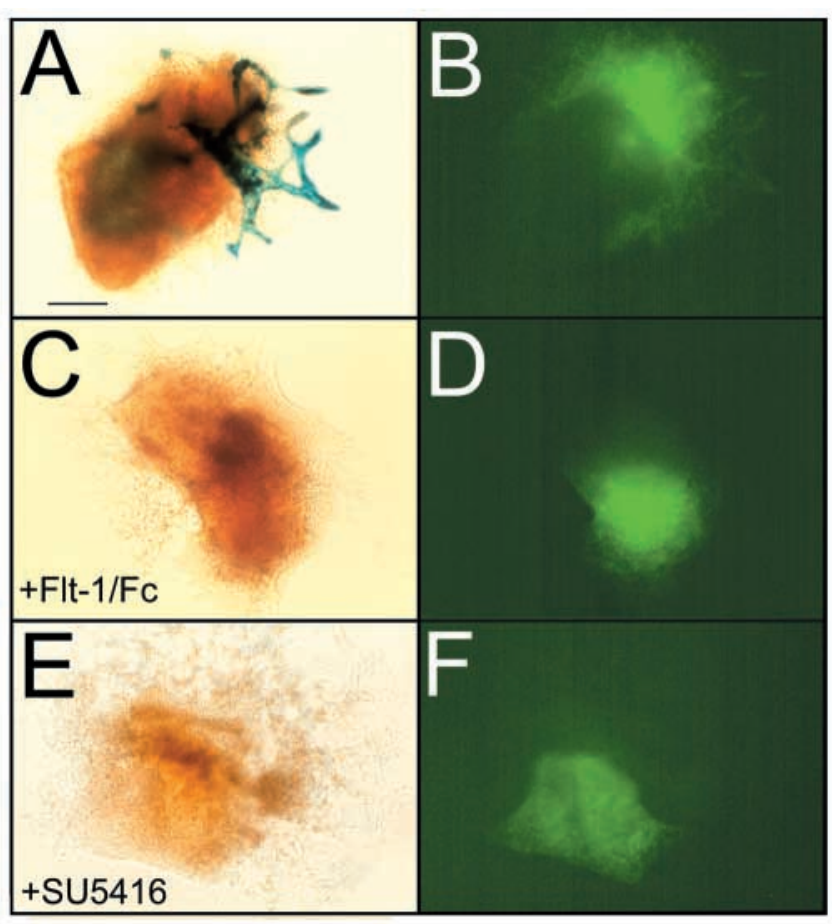

Fig. 7. Inhibitors of VEGF signaling block neural tube-derived

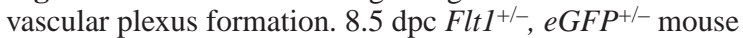
presomitic mesoderm grafts were placed beside stage $\mathrm{HH}$ 10-13 quail neural tubes in collagen gels and cultured for 72 hours. Panels on the right $(\mathrm{B}, \mathrm{D}, \mathrm{F})$ show eGFP expression that identifies mouse tissue. Co-cultures were grown in basal medium alone $(\mathrm{A}, \mathrm{B})$ or with added $1 \mu \mathrm{g} / \mathrm{ml} \mathrm{Flt/Fc} \mathrm{(C,D)} \mathrm{or} 10 \mu \mathrm{M}$ SU5416 (E,F). $n \geq 4$ for all three conditions. Scale bar: $200 \mu \mathrm{m}$ for all panels.

VEGFA, the mutant $\mathrm{Flkl}^{-{ }^{--}}$explants produced only a few, scattered $\beta$-gal-positive cells (Fig. 8A,B). Formation of a vascular plexus was also blocked in $F l k l^{-l-}$ presomitic mesoderm explants co-cultured with neural tube (Fig. 8C,D). Interestingly, the $\mathrm{Flkl}^{-{ }^{--}}$presomitic mesoderm/neural tube cocultures had more $\beta$-gal-positive presomitic mesoderm cells than did presomitic mesoderm incubated with VEGFA (compare Fig. 8B with 8D), suggesting that neural tube-derived signals other than VEGF modulate expression from the FlkI locus. However, this modulation does not extend to FLT1 expression, because $\beta$-gal expression from the Flt1 locus was absent when VEGFA signaling was blocked (Fig. 7C-F). In any case, blocking VEGF signaling either genetically or pharmacologically prevents neural tube-dependent vascular plexus formation from somitic mesoderm, showing that VEGFA is a required component of the neural tube vascular patterning signal.

\section{Discussion}

We have shown that: (1) the neural tube recruits a vascular plexus in a position-independent manner, (2) the neural tubederived signal(s) induce both differentiation and migration of angioblasts, and (3) neural tube-derived VEGFA is required for formation of a vascular plexus from somitic tissue. Taken together, these results identify the neural tube as a midline signaling center for vascular patterning in higher vertebrates.

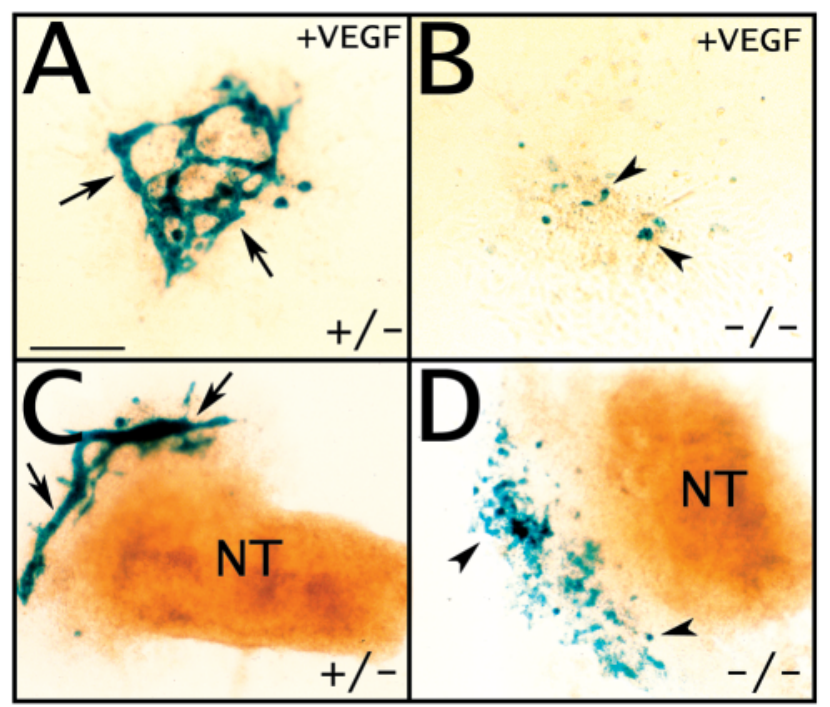

Fig. 8. A genetic mutation in the VEGF receptor Flkl blocks neural tube-derived vascular plexus formation. Mouse presomitic mesoderm explants were cultured for 72 hours in basal medium with either $30 \mathrm{ng} / \mathrm{ml}$ VEGFA (A,B) or stage HH10-13 quail neural tubes (C,D). Explants were either $F l k 1^{+/-}(\mathrm{A}, \mathrm{C})$ or $F l k 1^{-l-}(\mathrm{B}, \mathrm{D})$, and mouse vascular cells were visualized by $\beta$-gal staining. The arrows $(A, C)$ indicate mouse vascular plexus, and the arrowheads $(B, D)$ point to $\beta$ gal positive (blue) presumptive mouse vascular cells. $n \geq 7$ for all conditions. Scale bar: $200 \mu \mathrm{m}$ for all panels.

Neural tube-derived signal(s) act positively to recruit angioblasts and organize a perineural vascular plexus, and VEGFA is a necessary component of the neural tube vascular patterning signal (Fig. 9).

\section{The neural tube as a vascular signaling center}

This is, to our knowledge, the first demonstration that the neural tube patterns the vasculature around the midline. We directly tested the hypothesis that the neural tube is the source of a vascular patterning signal by moving it to an ectopic site in the embryo, and by analyzing a genetic mutation that results in ectopic neural tube formation. Our results show that the signal and the structure coincide. Interestingly, our results indicate that advanced neural tube patterning is not required for the production of the vascular patterning signal, as ectopic neural tubes removed from the influence of the notochord nevertheless recruit a vascular plexus. These neural tubes were removed from the region adjacent to the presomitic mesoderm of day $8.5 \mathrm{dpc}$ mouse or HH10-13 stage quail embryos, so they probably had floor plate specified but not more advanced neuronal cell types (Catala et al., 1996; Lee and Jessell, 1999). This suggests that interneurons and motoneurons that are induced by the notochord (Briscoe and Ericson, 1999) are not required to produce the neural tube vascular patterning signal(s) under investigation. The PNVP is unique in that it initially forms around the neural tube, but it does not invade the neural tissue until later in development. This suggests that the expression and magnitude of positive vascular patterning signals, and possible repulsive cues, are all co-regulated to lead to PNVP formation.

What is the source of angioblasts that colonize the PNVP? We and others have shown that somite-derived angioblasts 


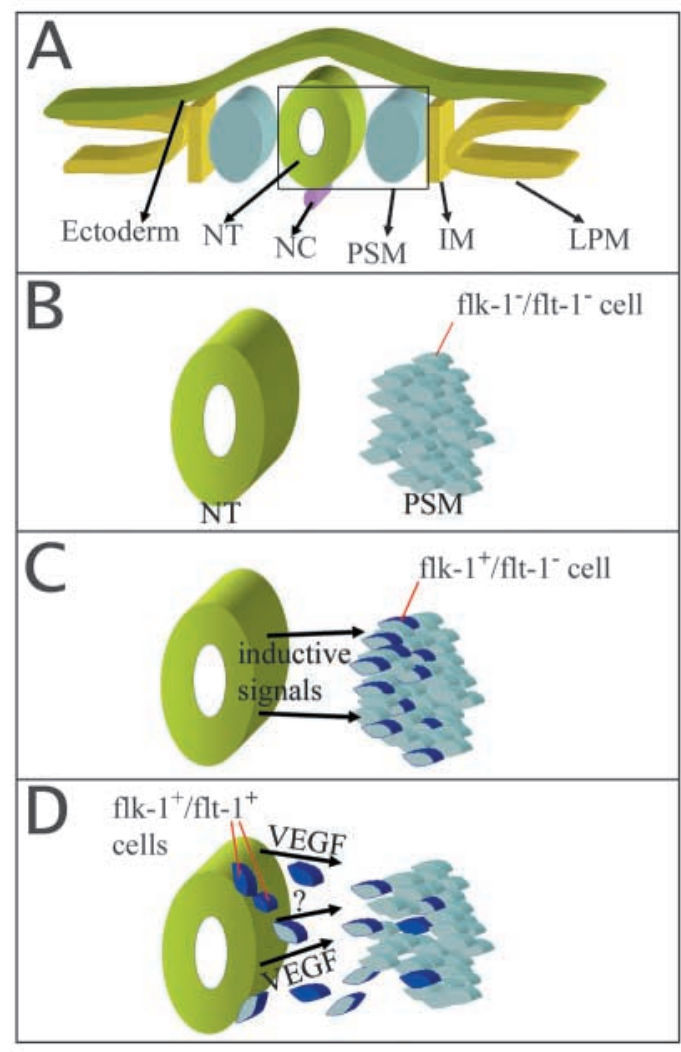

Fig. 9. Neural tube patterning of blood vessels - a model. (A) Diagram showing cross-sectional view of a mouse embryo at $8.5 \mathrm{dpc}$. The boxed area is enlarged in B-D. (B) Initially, the presomitic mesoderm does not contain committed vascular precursor cells. (C) A VEGF-independent signal induces FLK1 expression in a subset of presomitic mesoderm cells. (D) FLK1 expressing angioblasts are now competent to respond to the neural tube-derived VEGFA containing signal. The angioblasts now express additional vascular markers, such as FLT1, and they migrate and assemble the PNVP. Other unidentified signals emanating from the neural tube may also contribute to PNVP patterning in vivo. NT, neural tube; NC, notochord; PSM, presomitic mesoderm; IM, intermediate mesoderm; LPM, lateral plate mesoderm.

reproducibly contribute to PNVP formation (Wilting et al., 1995; Klessinger and Christ, 1996; Pardanaud et al., 1996; Pardanaud and Dieterlen-Lievre, 1999; Ambler et al., 2001), and in this study the neural tube was sufficient for formation of a somite-derived vascular plexus in collagen co-cultures. Presomitic mesoderm grafts placed next to a 'buffer' of avian cells that prevented direct contact with neural tube contributed to the PNVP, showing that progenitor/endothelial cells can migrate over a distance in response to neural tube vascular patterning signal(s). However, it is likely that other embryonic tissues also contribute endothelial/progenitor cells to PNVP formation. For example, the lateral plate mesoderm is a rich source of migratory angioblasts, and lateral plate grafts can contribute vascular cells to the PNVP (Noden, 1988; Poole and Coffin, 1989; Pardanaud et al., 1996; Cleaver and Krieg, 1998; Pardanaud and Dieterlen-Lievre, 1999; Childs et al., 2002). When neural tubes were placed adjacent to lateral plate mesoderm in our study, the ectopic PNVP that formed did not compromise PNVP formation around the endogenous neural tube. Thus, it is likely that angioblasts from the lateral plate mesoderm contributed to the ectopic PNVP, and that both somite-derived and lateral plate-derived angioblasts can respond to vascular patterning signal(s) from the neural tube. This idea is supported by the finding that $T b x 6$ mutant embryos do not have posterior somites (Chapman and Papaioannou, 1998), yet they have three posterior neural tubes that each have a PNVP.

\section{VEGFA, a neural tube-derived molecular mediator of vascular pattern}

The neural tube is a signaling center that organizes embryonic structures around the midline. Along with the notochord, somites, and overlying ectoderm, the neural tube produces molecular signals that pattern the neural tube itself, and the somites that form adjacent to the neural tube. Moreover, many of the molecules involved in these signals have been identified. For example, sclerotome is induced by Shh production from the floor plate (Fan and Tessier-Lavigne, 1994; Johnson et al., 1994), dermatome is patterned by secretion of neurotrophin 3 and Wnt1 from the neural tube (Brill et al., 1995; OliveraMartinez et al., 2001), and epaxial myoblasts are patterned by a combination of Shh, Wnt1 and Wnt3a (Munsterberg et al., 1995; Stern et al., 1995; Ikeya and Takada, 1998).

What molecular signals contribute to the neural tube-derived vascular patterning signal? The temporal and spatial expression pattern of VEGFA is consistent with it participating in a vascular patterning signal from the neural tube. To further dissect the neural tube vascular patterning signal(s), we adapted a co-culture system using a three-dimensional collagen matrix. This approach was successfully used to dissect the molecular components of neural pathfinding (Fan and TessierLavigne, 1994), but has not been previously applied to the analysis of vascular patterning signals. The co-culture of neural tube with presomitic mesoderm showed that the neural tube is sufficient to induce a vascular plexus from somitic tissue, and VEGFA can substitute for the neural tube and induce a vascular plexus from presomitic mesoderm in this model.

Our pharmacological and genetic manipulations of the VEGF signaling pathway indicate that it is a required component of the neural tube vascular patterning signal. Moreover, our results indicate that the signal is VEGFA, and that the relevant receptor is FLK1. SU5416 specifically inhibits signaling of the FLK1 receptor, and its presence in co-cultures resulted in a complete blockade of vascular plexus formation, as did genetic inactivation of $F l k l$. Flt/Fc is a soluble form of the FLT1 receptor that also completely blocked neural tubedependent vascular plexus formation. Flt $/ \mathrm{Fc}$ binds PLGF, VEGFA and VEGFB (Barleon et al., 1997; Olofsson et al., 1998), but of these three family members only VEGFA binds FLK1 (for a review, see Yancopoulos et al., 2000). Thus, the most likely molecular components of the neural tube vascular patterning signal are VEGFA and FLK1. We recently showed that VEGF signaling through FLK1 is crucial for patterning stem cell-derived endothelial cells/progenitors around the midline by analysis of mutant ES cell-derived grafts in avian hosts (Ambler et al., 2003). This work extends those findings to a requirement for FLK1 expression in somite-derived endothelial cells/progenitors to form and pattern a vascular plexus.

One caveat to the interpretation that VEGFA is a crucial 
neural tube-derived vascular patterning signal is that the VEGF signaling pathway is required for multiple steps in vascular development, including differentiation. Thus it could be argued that in the absence of VEGF signaling, the population of cells that respond to patterning signals is not present. Although we cannot formally exclude an exclusive role for VEGF in early specification of the vascular lineage, several lines of evidence suggest that VEGF signaling is not an absolute requirement for angioblast differentiation. Initial formation of murine endothelial cells and some vessels occurs in the absence of FLK1 in vivo and during ES cell differentiation, and zebrafish lacking FLK1 form many vessels but are defective in sprouting angiogenesis (Shalaby et al., 1995; Shalaby et al., 1997; Schuh et al., 1999; Habeck et al., 2002; Ambler et al., 2003). In the avian embryo, exogenous bFGF induces angioblasts, while VEGFA promotes angioblast migration and assembly (Cox and Poole, 2001; Poole et al., 2001; Finkelstein and Poole, 2003). In our study, VEGF signaling is not required to activate the FLK1 locus in a subset of presomitic mesoderm cells in the presence of neural tube (Fig. 8D), suggesting that cells can be specified to the vascular differentiation pathway in the absence of VEGF. Moreover, VEGF signaling clearly imparts information over and above that required for angioblast differentiation, as VEGFA could substitute for the neural tube in forming a presomitic mesoderm-derived vascular plexus, whereas bFGF, a second signal associated with angioblast induction, increased the number of vascular cells but did not induce assembly of a vascular plexus. It will be interesting to further dissect the requirement for VEGF signaling in vascular patterning using conditional targeting strategies and sitedirected mutagenesis of the FLK1 receptor.

As discussed above, the finding that $\mathrm{FlkI}^{-{ }^{-}}$presomitic mesoderm explants have more $\beta$-gal-positive cells when cultured with a neural tube than with exogenous VEGFA, suggests that a second neural tube signal contributes to induction of FLK1 expression (Fig. 9C). VEGF-independent Flk1 expression is also seen in hemizygous $\left(F l k 1^{++-}\right)$ presomitic mesoderm neural tube co-cultures incubated with $\mathrm{Flt} / \mathrm{Fc}$ (K.A.H. and V.L.B., unpublished). Thus, it is plausible that a VEGF-independent neural tube signal induces FlkI expression in a subset of somitic cells. Flkl-expressing cells would then be competent to respond to the signal that requires VEGFA, which is known to induce further differentiation, as followed by expression of vascular markers such as FLT1. VEGFA also induces migration of endothelial cells/progenitors and assembly of a vascular plexus (Fig. 9D). The ability of VEGFA to substitute for the neural tube in the co-culture experiments may be dose dependent, as preliminary results indicate that low concentrations of VEGFA do not support robust vascular plexus formation from presomitic mesoderm (K.A.H. and V.L.B., unpublished). This finding is consistent with a correlative study that associated tissues expressing high levels of VEGFA with vasculogenic colonization and tissues expressing lower levels of VEGFA with angiogenic colonization (Miquerol et al., 1999). It will be interesting to determine if neural tube signals other than VEGF play important roles in vivo.

The hypothesis that additional signals emanate from the neural tube also may explain a conundrum - the murine gut endoderm lies almost immediately ventral to the neural tube at E8.5, and expression of VEGFA RNA is significantly stronger from this embryonic structure than from the neural tube. Although the endoderm may be the source of a midline signal earlier in development that induces formation of the dorsal aorta (Cleaver and Krieg, 1998; Miquerol et al., 1999), at this stage the endoderm does not recruit a vascular plexus and the neural tube does recruit the PNVP. This suggests that VEGFA expression is not sufficient to induce a competition between endoderm and neural tube for somite-derived angioblasts. Thus, the neural tube may emit additional inductive and/or vascular patterning signals that co-operate with VEGFA to recruit the PNVP.

\section{Conclusions}

The identification of the neural tube as the source of a vascular patterning signal from the midline of the vertebrate embryo enhances our understanding of the basic processes of blood vessel formation, as vessels do not form and expand randomly, but in response to specific environmental cues. It also shows that embryonic tissues without endogenous capacity for vessel formation can nevertheless communicate with other embryonic compartments in a coordinated way, and recruit a vascular plexus to provide for metabolic needs. The placement of VEGFA in this signal pathway provides the beginnings of a mechanistic analysis of this process. A better understanding of how vascular pattern is controlled also has multiple ramifications in medical therapies and disease treatments. Specifically, our ability to induce appropriate neovascularization in patients to treat blockage of coronary and other vessels depends on understanding what cues normally pattern vessels, and how endothelial cells and their precursors respond to these cues. Likewise, the therapeutic goal of reconstituting blood vessels outside the body for grafting purposes will be facilitated with a better understanding of vascular patterning events.

We thank Guo Hua Fong for the Flt1 ${ }^{+/-}$mice and Andras Nagy for the Vegf-lacZ-K1 mice, which were provided by Pat D'Amore. We thank members of the Bautch Laboratory and the Cardiovascular Development Group for fruitful discussion, and Anthony LaMantia, Mark Majesky and Cam Patterson for critical reading of the manuscript. This work was supported by NIH R01 HL 43174 (V.L.B.), and AHA 0120572U and NIH F32 HL68484 (K.A.H.).

\section{References}

Aitkenhead, M., Christ, B., Eichmann, A., Feucht, M., Wilson, D. J. and Wilting, J. (1998). Paracrine and autocrine regulation of vascular endothelial growth factor during tissue differentiation in the quail. Dev. Dyn. 212, 1-13.

Ambler, C. A., Nowicki, J. L., Burke, A. C. and Bautch, V. L. (2001). Assembly of trunk and limb blood vessels involves extensive migration and vasculogenesis of somite-derived angioblasts. Dev. Biol. 234, 352364.

Ambler, C. A., Schmunk, G. A. and Bautch, V. L. (2003). Stem cell-derived endothelial cells/progenitors migrate and pattern in the embryo using the VEGF signaling pathway. Dev. Biol. 257, 205-219.

Bar, T. (1980). The vascular system of the cerebral cortex. Adv. Anat. Embryol. Cell Biol. 59, 1-62.

Barleon, B., Totzke, F., Herzog, C., Blanke, S., Kremmer, E., Siemeister, G., Marme, D. and Martiny-Baron, G. (1997). Mapping of the sites for ligand binding and receptor dimerization at the extracellular domain of the vascular endothelial growth factor receptor FLT-1. J. Biol. Chem. 272, 10382-10388.

Bates, D., Taylor, G. I., Minichiello, J., Farlie, P., Cichowitz, A., Watson, N., Klagsbrun, M., Mamluk, R. and Newgreen, D. F. (2003). 
Neurovascular congruence results from a shared patterning mechanism that utilizes Semaphorin3A and Neuropilin-1. Dev. Biol. 255, 77-98.

Bauer, H. C., Bauer, H., Lametschwandtner, A., Amberger, A., Ruiz, P. and Steiner, M. (1993). Neovascularization and the appearance of morphological characteristics of the blood-brain barrier in the embryonic mouse central nervous system. Dev. Brain Res. 75, 269-278.

Brill, G., Kahane, N., Carmeli, C., von Schack, D., Barde, Y. A. and Kalcheim, C. (1995). Epithelial-mesenchymal conversion of dermatome progenitors requires neural tube-derived signals: characterization of the role of Neurotrophin-3. Development 121, 2583-2594.

Briscoe, J. and Ericson, J. (1999). The specification of neuronal identity by graded Sonic Hedgehog signalling. Semin. Cell Dev. Biol. 10, 353-362.

Carmeliet, P., Ferreira, V., Breier, G., Pollefeyt, S., Kieckens, L., Gertsenstein, M., Fahrig, M., Vandenhoeck, A., Harpal, K., Eberhardt, C. et al. (1996). Abnormal blood vessel development and lethality in embryos lacking a single VEGF allele. Nature 380, 435-439.

Carmeliet, P., Ng, Y. S., Nuyens, D., Theilmeier, G., Brusselmans, K., Cornelissen, I., Ehler, E., Kakkar, V. V., Stalmans, I., Mattot, V. et al. (1999). Impaired myocardial angiogenesis and ischemic cardiomyopathy in mice lacking the vascular endothelial growth factor isoforms VEGF164 and VEGF188. Nat. Med. 5, 495-502.

Catala, M., Teillet, M. A., de Robertis, E. M. and le Douarin, M. L. (1996). A spinal cord fate map in the avian embryo: while regressing, Hensen's node lays down the notochord and floor plate thus joining the spinal cord lateral walls. Development 122, 2599-2610.

Chapman, D. L. and Papaioannou, V. E. (1998). Three neural tubes in mouse embryos with mutations in the T-box gene Tbx6. Nature 391, 695-697.

Childs, S., Chen, J. N., Garrity, D. M. and Fishman, M. C. (2002). Patterning of angiogenesis in the zebrafish embryo. Development 129, 973982.

Cleaver, O. and Krieg, P. A. (1998). VEGF mediates angioblast migration during development of the dorsal aorta in Xenopus. Development 125, 39053914.

Cleaver, O. and Melton, D. A. (2003). Endothelial signaling during development. Nat. Med. 9, 661-668.

Coffin, J. D. and Poole, T. J. (1991). Endothelial cell origin and migration in embryonic heart and cranial blood vessel development. Anat. Rec. 231, 383395.

Cox, C. M. and Poole, T. J. (2001). Angioblast differentiation is influenced by the local environment: FGF-2 induces angioblasts and patterns vessel formation in the quail embryo. Dev. Dyn. 218, 371-382.

Dent, J., Polson, A. G. and Klymkowsky, M. W. (1989). A whole-mount immunocytochemical analysis of the expression of the intermediate filament protein vimentin in Xenopus. Development 105, 61-74.

Evans, H. M. (1909). On the development of the aortae, cardinal and umbilical veins, and other blood vessels of the vertebrate embryos from vertebrates. Anat Rec 3, 498-518.

Fan, C. M. and Tessier-Lavigne, M. (1994). Patterning of mammalian somites by surface ectoderm and notochord: evidence for sclerotome induction by a hedgehog homolog. Cell 79, 1175-1186.

Ferrara, N. and Davis-Smyth, T. (1997). The biology of vascular endothelial growth factor. Endocrinol. Rev. 18, 4-25.

Finkelstein, E. B. and Poole, T. J. (2003). Vascular endothelial growth factor: a regulator of vascular morphogenesis in the Japanese quail embryo. Anat. Rec. 272A, 403-414.

Fong, G. H., Rossant, J., Gertsenstein, M. and Breitman, M. (1995). Role of the Flt-1 receptor tyrosine kinase in regulating the assembly of vascular endothelium. Nature 376, 66-70.

Fong, T. A. T., Shawver, L. K., Sun, L., Tang, C., App, H., Powell, T. J., Kim, Y. H., Schreck, R., Wang, X., Risau, W. et al. (1999). SU5416 is a potent and selective inhibitor of the vascular endothelial growth factor receptor (Flk-1/KDR) that inhibits tyrosine kinase catalysis, tumor vascularization, and growth of multiple tumor types. Cancer Res. 59, 99106.

Friedrich, G. and Soriano, P. (1991). Promoter traps in embryonic stem cells: a genetic screen to identify and mutate developmental genes in mice. Genes Dev. 5, 1513-1523.

Graef, I. A., Chen, F., Chen, L., Kuo, A. and Crabtree, G. R. (2001). Signals transduced by $\mathrm{Ca}(2+) /$ calcineurin and $\mathrm{NFATc} 3 / \mathrm{c} 4$ pattern the developing vasculature. Cell 105, 863-875.

Habeck, H., Odenthal, J., Walderich, B., Maischein, H. and SchulteMerker, S. (2002). Analysis of a zebrafish VEGF receptor mutant reveals specific disruption of angiogenesis. Curr. Biol. 12, 1405-1412.

Hadjantonakis, A. K., Gertsenstein, M., Ikawa, M., Okabe, M. and Nagy,
A. (1998). Generating green fluorescent mice by germline transmission of green fluorescent ES cells. Mech. Dev. 76, 79-90.

Hamburger, V. and Hamilton, H. L. (1951). A series of normal stages in the development of the chick embryo. J. Morphol. 88, 49-92.

Hogan, B. L. and Kolodziej, P. A. (2002). Organogenesis: molecular mechanisms of tubulogenesis. Nat. Rev. Genet. 3, 513-523.

Ikeya, M. and Takada, S. (1998). Wnt signaling from the dorsal neural tube is required for the formation of the medial dermomyotome. Development 125, 4969-4976.

Johnson, R. L., Laufer, E., Riddle, R. D. and Tabin, C. (1994). Ectopic expression of Sonic hedgehog alters dorsal-ventral patterning of somites. Cell 79, 1165-1173.

Kaufman, M. H. (1992). In The Atlas of Mouse Development, p. 79. Amsterdam, The Netherlands: Elsevier.

Keyt, B. A., Berleau, L. T., Nguyen, H. V., Chen, H., Heinsohn, H., Vandlen, R. and Ferrara, N. (1996). The carboxyl-terminal domain (111165) of vascular endothelial growth factor is critical for its mitogenic potency. J. Biol. Chem. 271, 7788-7795.

Klessinger, S. and Christ, B. (1996). Axial structures control laterality in the distribution pattern of endothelial cells. Anat. Embryol. 193, 319-330.

Lawson, N. D., Scheer, N., Pham, V. N., Kim, C. H., Chitnis, A. B., Campos-Ortega, J. A. and Weinstein, B. M. (2001). Notch signaling is required for arterial-venous differentiation during embryonic vascular development. Development 128, 3675-3683.

Lee, K. J. and Jessell, T. M. (1999). The specification of dorsal cell fates in the vertebrate central nervous system. Annu. Rev. Neurosci. 22, 261-294.

Miquerol, L., Gertenstein, M., Harpal, K., Rossant, J. and Nagy, A. (1999). Multiple developmental roles of VEGF suggested by a lacZ-tagged allele. Dev. Biol. 212, 307-322.

Mukouyama, Y. S., Shin, D., Britsch, S., Taniguchi, M. and Anderson, D. J. (2002). Sensory nerves determine the pattern of arterial differentiation and blood vessel branching in the skin. Cell 109, 693-705.

Munsterberg, A. E., Kitajewski, J., Bumcrot, D. A., McMahon, A. P. and Lassar, A. B. (1995). Combinatorial signaling by Sonic hedgehog and Wnt family members induces myogenic bHLH gene expression in the somite. Genes Dev. 9, 2911-2922.

Nakao, K., Ishizawa, A. and Ogawa, R. (1988). Observations of vascularization in the spinal cord of mouse embryos, with special reference to development of boundary membranes and perivascular spaces. Anat. Rec. 221, 663-677.

Ng, Y. S., Rohan, R., Sunday, M. E., Demello, D. E. and D'Amore, P. A. (2001). Differential expression of VEGF isoforms in mouse during development and in the adult. Dev. Dyn. 220, 112-121.

Noden, D. M. (1988). Interactions and fates of avian craniofacial mesenchyme. Development 103, 121-140.

Olivera-Martinez, I., Thelu, J., Teillet, M. A. and Dhouailly, D. (2001). Dorsal dermis development depends on a signal from the dorsal neural tube, which can be substituted by Wnt-1. Mech. Dev. 100, 233-244.

Olofsson, B., Korpelainen, E., Pepper, M. S., Mandriota, S. J., Aase, K., Kumar, V., Gunji, Y., Jeltsch, M. M., Shibuya, M., Alitalo, K. et al. (1998). Vascular endothelial growth factor B (VEGF-B) binds to VEGF receptor-1 and regulates plasminogen activator activity in endothelial cells. Proc. Natl. Acad. Sci. USA 95, 11709-11714.

Otani, A., Kinder, K., Ewalt, K., Otero, F. J., Schimmel, P. and Friedlander, M. (2002). Bone marrow-derived stem cells target retinal astrocytes and can promote or inhibit retinal angiogenesis. Nat. Med. 8, 1004-1010.

Pardanaud, L. and Dieterlen-Lievre, F. (1999). Manipulation of the angiopoietic/hemangiopoietic commitment in the avian embryo. Development 126, 617-627.

Pardanaud, L., Luton, D., Prigent, M., Bourcheix, L. M., Catala, M. and Dieterlen-Lievre, F. (1996). Two distinct endothelial lineages in ontogeny, one of them related to hemopoiesis. Development 122, 1363-1371.

Pardanaud, L., Yassine, F. and Dieterlen-Lievre, F. (1989). Relationship between vasculogenesis, angiogenesis and haemopoiesis during avian ontogeny. Development 105, 473-485.

Park, J. E., Keller, G. A. and Ferrara, N. (1993). The vascular endothelial growth factor (VEGF) isoforms: differential deposition into the subepithelial extracellular matrix and bioactivity of extracellular matrix-bound VEGF. Mol. Biol. Cell 4, 1317-1326.

Pereria, F. A., Qiu, Y., Zhou, G., Tsai, M. J. and Tsai, S. Y. (1999). The orphan nucear receptor COUP-TFII is required for angiogenesis and heart development. Genes Dev. 13, 1037-1049.

Poole, T. J. and Coffin, J. D. (1989). Vasculogenesis and angiogenesis: two 
distinct morphogenetic mechanisms establish embryonic vascular pattern. $J$. Exp. Zool. 251, 224-231.

Poole, T. J., Finkelstein, E. B. and Cox, C. M. (2001). The role of FGF and VEGF in angioblast induction and migration during vascular development. Dev. Dyn. 220, 1-17.

Quinn, P., Barros, C. and Whittingham, D. G. (1982). Preservation of hamster oocytes to assay the fertilizing capacity of human spermatozoa. $J$. Reprod. Fertil. 66, 161-168.

Risau, W. (1986). Developing brain produces an angiogenesis factor. Proc. Natl. Acad. Sci. USA 83, 3855-3859.

Risau, W. (1997). Mechanisms of angiogenesis. Nature 386, 671-674.

Risau, W. and Wolburg, H. (1990). Development of the blood-brain barrier. Trends Neurosci. 13, 174-178.

Ruhrberg, C., Gerhardt, H., Golding, M., Watson, R., Ioannidou, S., Fujisawa, H., Betsholtz, C. and Shima, D. T. (2002). Spatially restricted patterning cues provided by heparin-binding VEGF-A control blood vessel branching morphogenesis. Genes Dev. 16, 2684-2698.

Schuh, A. C., Faloon, P., Hu, Q. L., Bhimani, M. and Choi, K. (1999). In vitro hematopoietic and endothelial potential of flk-1(-1-) embryonic stem cells and embryos. Proc. Natl. Acad. Sci. USA 96, 2159-2164.

Shalaby, F., Ho, J., Stanford, W. L., Fischer, K. D., Schuh, A. C., Schwartz, L., Bernstein, A. and Rossant, J. (1997). A requirement for Flk1 in primitive and definitive hematopoiesis and vasculogenesis. Cell 89, 981-990.

Shalaby, F., Rossant, J., Yamaguchi, T. P., Gertsenstein, M., Wu, X. F., Breitman, M. L. and Schuh, A. C. (1995). Failure of blood-island formation and vasculogenesis in Flk-1-deficient mice. Nature 376, 62-66.

Stalmans, I., Ng, Y. S., Rohan, R., Fruttiger, M., Bouche, A., Yuce, A.,
Fujisawa, H., Hermans, B., Shani, M., Jansen, S. et al. (2002). Arteriolar and venular patterning in retinas of mice selectively expressing VEGF isoforms. J. Clin. Invest. 109, 327-336.

Stern, H. M., Brown, A. M. and Hauschka, S. D. (1995). Myogenesis in paraxial mesoderm: preferential induction by dorsal neural tube and by cells expressing Wnt-1. Development 121, 3675-3686.

Stone, J., Itin, A., Alon, T., Pe'er, J., Gnessin, H., Chan-Ling, T. and Keshet, E. (1995). Development of retinal vasculature is mediated by hypoxia-induced vascular endothelial growth factor (VEGF) expression by neuroglia. J. Neurosci. 15, 4738-4747.

Wilting, J., Brand-Saberi, B., Huang, R., Zhi, Q., Kontges, G., Ordahl, C. P. and Christ, B. (1995). Angiogenic potential of the avian somite. Dev. Dyn. 202, 165-171.

Yancopoulos, G. D., Davis, S., Gale, N. W., Rudge, J. S., Wiegand, S. J. and Holash, J. (2000). Vascular-specific growth factors and blood vessel formation. Nature 407, 242-248.

Zelzer, E., McLean, W., Ng, Y. S., Fukai, N., Reginato, A. M., Lovejoy, S., D'Amore, P. A. and Olsen, B. R. (2002). Skeletal defects in VEGF(120/120) mice reveal multiple roles for VEGF in skeletogenesis. Development 129, 1893-1904.

Zhang, Y., Porat, R. M., Alon, T., Keshet, E. and Stone, J. (1999). Tissue oxygen levels control astrocyte movement and differentiation in developing retina. Dev. Brain Res. 118, 135-145.

Zhong, T. P., Rosenberg, M., Mohideen, M. A. P. K., Weinstein, B. M. and Fishman, M. C. (2000). Gridlock, and HLH gene required for assembly of the aorta in zebrafish. Science 287, 1820-1824.

Zhong, T. P., Childs, S., Leu, J. P. and Fishman, M. C. (2001). Gridlock signalling pathway fashions the first embryonic artery. Nature 414, 216-220. 